\title{
ANALISIS STRUKTUR LAPISAN BAWAH \\ PERMUKAAN MENGGUNAKAN METODE \\ GEOLISTRIK (STUDI KASUS PADA KAMPUS III \\ IAIN IMAM BONJOL PADANG DI SUNGAI BANGEK \\ KECAMATN KOTO TANGAH)
}

\author{
Hurriyah $^{1)}$ Raudatul Jannah2 ${ }^{2)}$ \\ 1) Jurusan Tadris IPA Fisika IAIN Imam Bonjol Padang \\ Hurriyah_iain@gmail.com \\ 2) Jurusan Tadris IPA Fisika IAIN Imam Bonjol Padang \\ Jannahraudatul@gmail.com
}

\begin{abstract}
The purpose of this research is to know about the structure of subsurface in campus III IAIN Imam Bonjol Padang. Information about subsurface used to preeleminary research as a base of planning office and classroom on new campus IAIN Imam Bonjol at Sungai Bangek. This Research use geophysical properties, specially Geoelectrical method. Geoelectrical method use electrical property of the earth through the subsurface and then record by geophone on the surface. The interpretation of the subsurface was do according to different of their resistivity. The result of this research shows that structure of this area dominate by clay, limestone, and andesit. The surface dominate by clay, andesit only in a few area. In subsurface andesit in range 45-60 meter.

Kata Kunci: Structure of subsurface, geoelectric, clay, limestone, andesit
\end{abstract}

\begin{abstract}
Abstrak
Tujuan dari penelitian ini adalah untuk mengetahui tentang struktur bawah permukaan di kampus III IAIN Imam Bonjol Padang. Informasi tentang bawah permukaan digunakan untuk penelitian preeleminary sebagai dasar dari kantor perencanaan dan kelas di kampus baru IAIN Imam Bonjol di Sungai Bangek. Penelitian ini menggunakan properti geofisika, metode khusus geolistrik. Metode geolistrik menggunakan properti listrik dari bumi melalui bawah permukaan dan kemudian merekam dengan geophone di permukaan. Interpretasi bawah permukaan itu dilakukan sesuai dengan yang berbeda dari tahanan mereka. Hasil penelitian ini menunjukkan bahwa struktur daerah ini mendominasi dengan tanah liat, kapur, dan andesit. permukaan mendominasi dengan tanah liat, andesit hanya dalam beberapa daerah. Di bawah permukaan andesit di kisaran 45-60 meteran.
\end{abstract}

\section{PENDAHULUAN}

IAIN Imam Bonjol Padang akan meningkatkkan statusnya menjadi UIN. Banyak upaya dilakukan untuk memperbaiki dan meningkatkan mutu Institusi demi peningkatan kualitas akademik. Salah satu penujang rencana tersebut adalah membangun kampus baru di daerah Sungai Bangek kecamatan Koto Tangah Padang. Masalah yang dihadapi sekarang adalah bagaimana merancang bangunan yang kuat, tahan lama, dan tepat guna. Hal ini salah satunya terkait dengan wilayah sumatera barat yang rawan bencana gempa bumi.

Suatu bangunan yang berdiri di atas tanah akan menimbulkan beban terhadap bawah tanah. Tanah akan mengalami tegangan tergantung beban yang dipikul dan 
luas pondasi yang digunakan. Akibatnya terjadi tegangan di bawah tanah, sehingga timbul perubahan bentuk (deformasi) dan penurunan (settlement) terhadap bangunan yang bersangkutan.

Perencanaan pembangunan yang cukup matang sangat diperlukan untuk mencegah timbulnya perubahan bentuk yang kemudian akan menyebabkan penurunan pada bangunan. Suatu bangunan yang dibangun tanpa memperhatikan struktur tanah dan tata lingkungan maka akan memiliki resiko yang lebih besar terhadap kerusakan akibat dari gempa maupun penurunan tanah.

Salah satu metode yang bisa digunakan untuk melihat struktur lapisan bawah permukaan adalah metode geolistrik. Metode geolistrik adalah metode geofisika yang efektif digunakan untuk eksplorasi dangkal. Metode ini memanfaatkan arus listrik yang diinjeksikan ke bawah permukaan bumi, kemudian dipantulkan kembali dan dicatat oleh receiver di atas permukaan. Dengan memanfaatkan sifat kelistrikan bumi diharapkan dapat diperoleh informmasi tentang lapisan bawah permukaan. Geolistrik Dalam hal ini meliputi pengukuran potensial, arus dan medan elektromagnetik yang terjadi baik secara alamiah ataupun akibat injeksi arus ke dalam bumi. Ada beberapa macam metoda geolistrik, antara lain: metoda potensial diri, arus telluric, magnetotelluric, IP (Induced Polarization), resistivitas (tahanan jenis) dan lainlain. Dalam penelitian kali ini, dibahas khusus metoda geolistrik tahanan jenis(resistivitas). Pada metoda geolistrik tahanan jenis ini, arus listrik diinjeksikan ke dalam bumi melalui dua elektroda arus. Kemudian beda potensial yang terjadi diukur melalui dua elektroda potensial. Dari hasil pengukuran arus dan beda potensial untuk setiap jarak elektroda yang berbeda kemudian dapat diturunkan variasi harga hambatan jenis masing-masing lapisan dibawah titik ukur (soundingpoint).

Fokus penelitian ini adalah meneliti lapisan tanah untuk mengetahui struktur lapisan bawah permukaaan IAIN Imam Bonjol Padang. Diharapkan informasi struktur lapisan bawah permukaan bisa digunakan sebagai acuan untuk rencana pembangunan gedung perkuliahan dan kantor IAIN Imam Bonjol Padang yang baru di Sungai Bangek kecamatan koto tangah Padang oleh pihak pengembang sehingga diharapkan dapat meminimalisir dampak kerusakan jika terjadi bencana alam seperti gempa. Masalah dalam penelitian ini dirumuskan sebagai berikut: 
Bagaimana struktur lapisan bawah permukaan kampus III IAIN Imam Bonjol di Sungai Bangek

\section{Sifat Listrik Batuan}

Aliran arus listrik didalam batuan/mineral dapat digolongkan menjadi tiga macam, yaitu konduksi secara elektronik, konduksi secara elektrolitik dan konduksi secara dielektrik. Konduksi secara elektronik terjadi jika batuan/mineral mempunyai banyak elektron bebas sehingga arus listrik dialirkan dalam batuan/mineral tersebut oleh elektron-elektron bebas itu. Konduksi elektrolitik terjadi jika batuan/mineral bersifat porus dan pori-pori tersebut terisi oleh cairan-cairan elektrolitik. Pada konduksi ini arus listrik dibawa oleh ion-ion elektrolit. Sedang konduksi dielektrik terjadi jika batuan/mineral bersifat dielektrik terhadap aliran arus listrik yaitu terjadi polarisasi saat bahan dialiri listrik. ${ }^{2}$

Harga-harga tahanan jenis tersebut dapat dilihat pada table 1 di bawah ini.

Table 1: Harga tahanan jenis beberapa material

\begin{tabular}{|l|l|l|}
\hline Material & Resistivity $(\Omega \mathrm{m})$ & Conductivity $(1 / \Omega \mathrm{m})$ \\
\hline Igneous and metamorphic Rock & & \\
Granite & $5 \times 10^{3}-10^{6}$ & $10^{-6}-2 \times 10^{-4}$ \\
Basalt & $10^{3} .10^{6}$ & $10^{-6}-10^{-3}$ \\
Slate & $6 \times 10^{2}-4 \times 10^{7}$ & $2.5 \times 10^{-8}-7 \times 10^{-3}$ \\
Marble & $10^{2}-2.5 \times 10^{8}$ & $4 \times 10^{-9}-10^{-2}$ \\
Quartzite & $10^{2}-2 \times 10^{8}$ & \\
Sedimentary Rock & & \\
Sandstone & $8-4 \times 10^{3}$ & $2.5 \times 10^{-4}-0.125$ \\
Shale & $20-2 \times 10^{8}$ & $5 \times 10^{-4}-0.05$ \\
Lime stone & $50-4 \times 10^{2}$ & $2.5 \times 10^{-3}-0.002$ \\
& & \\
\hline
\end{tabular}

Berdasarkan harga resistivitas listriknya, batuan/mineral digolongkan menjadi tiga yaitu:

Konduktor baik : $10-8<\rho<1 \Omega \mathrm{m}$

Konduktor pertengahan : $1<\rho<107 \Omega \mathrm{m}$

Isolator : $\rho>107 \Omega \mathrm{m}$

Tahanan jenis batuan yang terdapat dalam berbagai macan komposisi mineral di bumi tidak mempunyai harga tahanan jenis tertentu akan tetapi nilainya mempunyai range (jangkauan) tertentu. Secara teoritis setiap batuan memiliki daya hantar listrik dan harga tahanan jenisnya masing-masing. Batuan yang sama belum 
tentu mempunyai nilai tahanan jenis yang sama. Sebaliknya harga tanahan jenis yang sama bias dimiliki oleh batuan yang berbeda jenis. Faktor-faktor yang berpengaruh terhadap nilai tahanan jenis antara lain : komposisi mineral pada batuan, kondisi batuan, komposisi benda cair pada batuan, dan faktor ekstemal lainnya. Beberapa aspek yang berpengaruh pada tahanan jenis suatu batuan, adalah:

Batuan sedimen yang bersifat lepas (urai) mempunyai nilai tahanan jenis lebih rendah bila dibandingkan dengan batuan sedimen padat dan kompak.

a. Batuan beku dan metamorf (ubahan) mempunyai nilai tanahan jenis yang tergolong tinggi.

b. Batuan yang basah dan mengandung air, nilai tahanan jenisnya rendah, dan semakin lebih rendah lagi bila air yang dikandungnya bersifat payau atau asin.

Selain faktor diatas dalam pengambilan data lapangan perlu diperhitungkan factor luar seperti: kabel, tianglistrik, dan saluran pipa logam dapat mempengaruhi akurasi data lapangan.

\section{Metode Geolistrik}

Geolistrik merupakan salah satu metoda geofisika yang mempelajari sifat aliran listrik didalam bumi dan bagaimana cara mendeteksinya di dalam bumi dan bagaimana cara mendeteksinya di permukaan bumi. Dalam hal ini meliputi pengukuran potensial, arus dan medan elektromagnetik yang terjadi baik secara alamiah ataupun akibat injeksi arus ke dalam bumi. Ada beberapa macam metoda geolistrik, antara lain : metoda potensial diri, arus telluric, magnetotelluric, IP (Induced Polarization) dan resistivitas (tahanan jenis).

Pada metoda geolistrik tahanan jenis, arus listrik diinjeksikan kedalam bumi melalui dua elektroda arus. Kemudian beda potensial yang terjadi diukur melalui dua elektroda potensial. Dari hasil pengukuran arus dan beda potensial untuk setiap jarak elektroda yang berbeda kemudian dapat diturunkan variasi harga hambatan jenis masing-masing lapisan dibawah titik ukur (sounding point). Keunggulan dari metode geolistrik adalah harga peralatan dan biaya survey relatif murah. Tidak membutuhkan waktu yang lama, peralatan relatif ringan sehingga lebih memudahkan untuk mobilisasi dibandingkan dengan penggunaan metode lain4.

Metoda ini lebih efektif jika digunakan untuk eksplorasi yang sifatnya dangkal, jarang memberikan informasi lapisan di kedalaman lebih dari 1000 feet 
atau 1500 feet. Oleh karena itu metoda ini jarang digunakan untuk eksplorasi minyak tetapi lebih banyak digunakan dalam bidang engineering geology seperti penentuan kedalaman batuan dasar, pencarian reservoar air, juga digunakan dalam eksplorasi geotermal.

\section{Resistivitas semu}

Pengukuran resistivitas dilakukan terhadap permukaan bumi yang di anggap sebagai suatu medium yang homogen isotropis. Pada kenyataannya, bumi tersusun atas komposisi batuan yang bersifat heterogen baik ke arah vertikal maupun horisontal. Akibatnya objek batuan yang tidak homogen dan beragam akan memberikan harga resistivitas yang beragam pula. Sehingga resistivitas yang diukur adalah resistivitas semu. Harga tahanan jenis semu ini tergantung pada tahanan jenis lapisan-lapisan pembentuk formasi dan konfigurasi elektroda yang digunakan. Tahanan jenis semu dirumuskan sebagai:

$$
\rho_{a}=K \frac{\Delta V}{I} ; R=\frac{\Delta V}{I}
$$

Dengan $K$ adalah faktor geometri susunan elektroda yang berdimensi panjang. Beberapa hal yang mempengaruhi nilai resistivitas semu adalah sebagai berikut (Prasetiawati, 2004):

a. Ukuran butir penyusun batuan, semakin kecil besar butir maka kelolosan arus akan semakin baik, sehingga mereduksi nilai tahanan jenis.

b. Komposisi mineral dari batuan, semakin meningkat kandungan mineral clay akan mengakibatkan menurunnya nilai resisivitas.

c. Kandungan air, air tanah atau air permukaan merupakan media yang mereduksi nilai tahanan jenis.

d. Kelarutan garam dalam air di dalam batuan akan mengakibatkan meningkatnya kandungan ion dalam air sehingga berfungsi sebagai konduktor.

e. Kepadatan, semakin padat batuan akan meningkatkan nilai resistivitas.

\section{METODOLOGI}

1. Subjek Penelitian

Subjek penelitian ini adalah tanah milik IAIN Imam Bonjol Padang yang baru di sungai Bangek Kecamatan Koto Tangah. Populasi penelitian ini adalah seluruh tanah milik IAIN Imam Bonjol Padang di Sungai Bangek seluas 60 Hektar. Sedangkan 
pengambilan sampelnya secara random sampling, di ambil sebanyak empat lintasan (satu lintasan sepanjang 300 meter) di tempat yang berbeda.

2. Jenis dan Sumber Data Penelitian

Data yang digunakan adalah data primer dan sekunder. Data primer berupa pengukuran langsung menggunakan metoda Geolistrik dan data sekunder berupa data geologi kota Padang. Populasi dari penelitian ini adalah seluruh tanah milik IAIN Imam Bonjol Padang di Sungai Bangek. Satu lintasan 300 meter. Variabel diukur adalah beda potensial bumi (V), dan arus listrik (I), sehinggga bisa didapatkan secara perhitungan melalui persamaan matematika resistivitas semu (). Data ini kemudian diolah menggunakan program komputer Res2Div untuk mendapatkan citra bawah permukaan. Penampang resisitivitas semu yang telah diperoleh digunakan untuk menginterpolasi data resisitivitas semu ideal dengan asumsi bahwa perlapisan bawah permukaan antar titik pengukuran saling berhubungan. Hasil interpolasi dijadikan input untuk melakukan pemodelan lapisan resistivitas tanah bawah perrnukaan dengan bantuan komputer.

3. Prosedur Penelitian

Ada tiga tahapan dalam penelitian ini:

a. Pengambilan data (acquisition)

Pengambilan data menggunakan bentangan elektroda dengan konfigurasi wenner untuk data profiling dan konfigurasi schlumberger untuk data sounding. Pengambilan data ini membutuhkan peralatan lapangan.

Langkah-langkah pengumpulan data:

- Menyusun alat menurut konfigurasi Wenner-Schlumberger sesuai dengan prinsip kerja alat

- Menentukan jarak antara elektroda.

- Mengaktifkan alat ukur resistivitymeter.

- Membaca besarnya beda potensial yang terjadi antara dua elektroda (V), arus listrik yang mengalir (I)

b. Pengolahan data (processing)

Pengolahan data dilakukan menggunakan software Res2Div

c. Interpretasi data (interpretation)

Setelah data diolah menggunakan Res2Div, dilakukan interpretasi sstruktur bawah permukaan terhadap kedalaman. Tujuannya adalah untuk mendapatkan True 
Resistivity dan True Depth. Interpretasi data ini menggunakan software Res2Div. Hasil pengolahan data diintepretasikan sehingga diperoleh struktur bawah permukaan berdasarkan harga tahanan jenis yang diperoleh. Jika diperoleh hasil yang sesuai maka dapat disimpulkan struktur yang dipelajari dan perkiraan material yang terkandung didalamnya berdasarkan pada acuan table tahanan jenis, selanjutnya dicocokkan dengan peta geologi setempat.

\section{PEMBAHASAN}

Lintasan yang digunakan terletak pada koordinat 000. 48'.32,7'- 000. 48'. 42, 0'LS 100. 22'. 19, 1'-100. 22'. 21, 4”BT. Data yang diperlukan dalam penelitian ini adalah informasi arus yang digunakan (elektroda arus dalam mA), beda potensial (elektroda potensial dalam $\mathrm{mV}$ ), bentangan yang digunakan (wenner Schlumberger), dan resistivitas semu (apparent resistivity dalam ohmmeter).

Berikut ini akan dipaparkan data hasil pengukuran yang diperoleh untuk masing-masing lintasan. Hasil berikut telah diolah menggunakan software Res2Div.

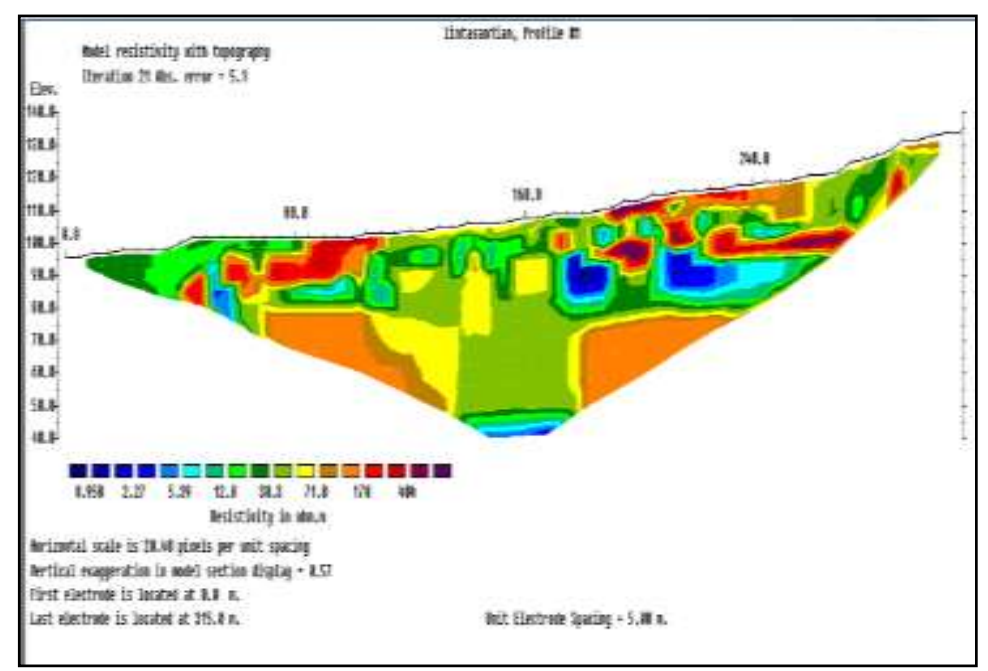

Gambar 1: Hasil Res2Div Lintasan 1

Data di atas merupakan hasil pengukuran langsung menggunakan automatic resistivity. Lintasan satu terletak pada koordinat: S: 000.48'.39,7”000.48'91,6”; E: 1000.22'.09,2” - 1000.22'.19,0”. Lokasi ini terletak pada ketinggian 96-134 meter dari permukaan laut. Kedalaman penetrasi yang diperoleh adalah 60 meter dan panjang lintasan 315 meter. data yang diperoleh didapatkan range resitivitas bawah permukaan daerah penelitian untuk lintasan 1 adalah 0,1 $500 \Omega \mathrm{m}$. Lapisan atas di lintasan 1 didominasi oleh clay bercampur air, hal ini terlihat dari lintasan 0-80 meter. Lapisan batuan keras juga terlihat pada jarak 80- 
100 meter dari titik awal pengukuran dan pada jarak 200-240 meter. Hal ini sesuai dengan kenampakan geologi di permukaan.

Nilai tahanan jenis (resistivitas) pada lokasi ini berkisar antara 1-450 $\Omega \mathrm{m}$. Nilai tahanan jenis rendah yang ditunjukkan oleh warna biru,berkisar antara 1-12,7 $\Omega \mathrm{m}$ diinterpretasi sebagai clay basah atau terkontaminasi air. Nilai tahanan jenis 12,8-39,3 $\Omega \mathrm{m}$ adalah clay yang lebih padat. Limestone terdapat pada nilai tahanan jenis berkisar antara 39,3-170 $\Omega \mathrm{m}$. Tahanan jenis besar dari $170 \Omega \mathrm{m}$ diidentifikasi sebagai batuan beku andesit.

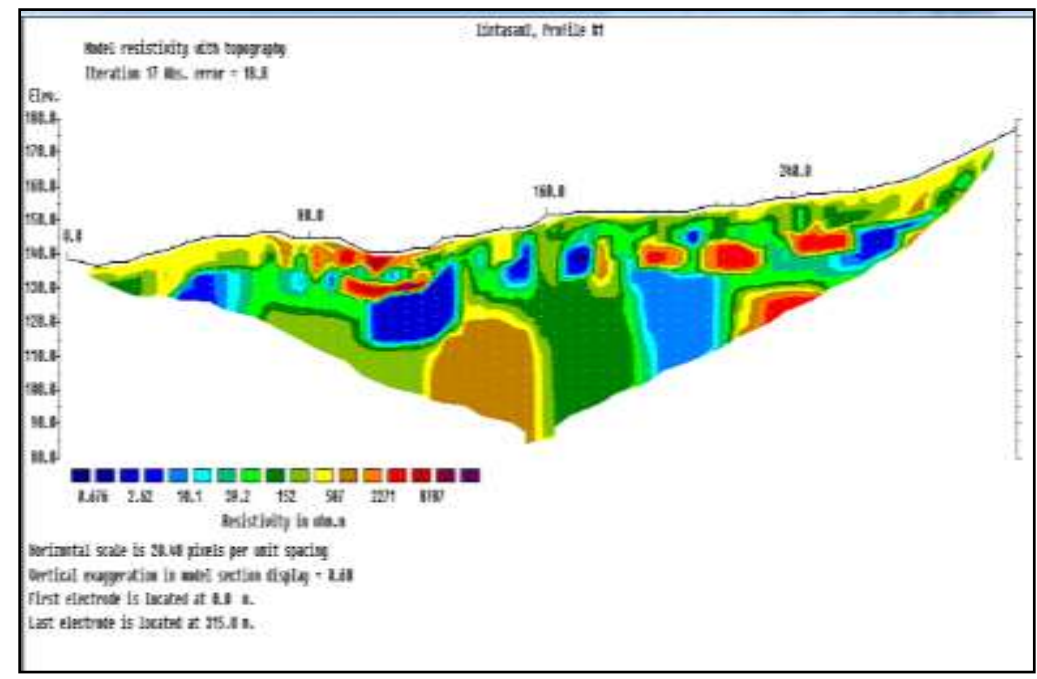

Gambar 2: Hasil Res2Div lintasan 2

Gambar 2 diatas menunjukkan range resitivitas bawah permukaan daerah penelitian untuk lintasan 2 adalah 0,1-9000 $\Omega \mathrm{m}$. Posisi lintasan berada pada koordinat S: 00.48'.32,7”-00.48'.42,0”; E: 100.22'.19,1”-100.22'.21,4”. Lapisan ata padas lintasan 2 didominasi oleh clay padat dan limestone, hal ini terlihat pada hampir seluruh permukaan. Lapisan batuan keras juga terlihat pada jarak 80-100 meter dari titik awal pengukuran. Hal ini sesuai dengan kenampakan geologi di permukaan.

Nilai tahanan jenis pada lapisan batuan lintasan ini bervariasi sesuai dengan batuan yang terdapat dibawahnya. Lapisan yang terdiri dari clay basah memiliki range tahanan jenis yang rendah yaitu $<10 \Omega \mathrm{m}$, ditandai oleh warna biru muda sampai biru tua pada kenampakan Res2Div. Selanjutnya tahanan jenis antara 10$160 \Omega \mathrm{m}$ diidentifikasi sebagai lapisan clay yang lebih padat. Batuan limestone dengan range tahanan jenis 160- $400 \Omega$ m terlihat berada dibawah lapisan clay, yang menyangga lapisan atas tersebut, karena batuan ini lebih padat. Batuan keras dan padat dengan tahanan jenis besar dari $400 \Omega \mathrm{m}$ terdapat di beberapa bagian yang 
bervariasi terhadap kedalaman. Lapisan batuan ini juga muncul di permukaan berupa bongkahan batu-batu besar
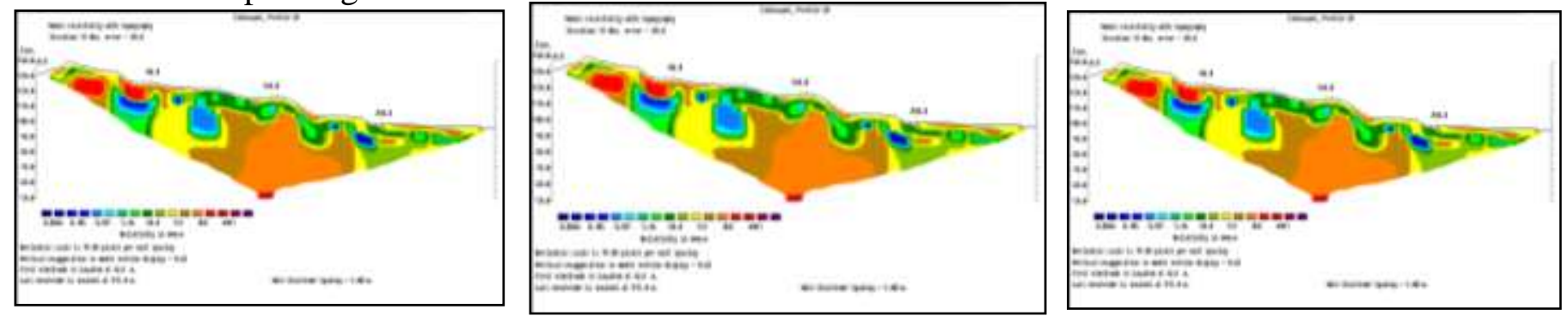

Gambar 3. Hasil Res2Div Lintasan 3

Lintasan 3 diambil sejajar dengan lintasan 1 terletak pada 000. 48'. 41, 4” 000. 48'. 44"'LS dan 100. 22'. 10, 1"-100. 22'. 19, 6" BT. Elevasi lokasi ini adalah 96-139 meter di atas permukaan laut. Lintasan 3 seperti terlihat dalam data ketinggiannya bervariasi sampai 43 meter, dengan kemiringan hampir 450. Pengukuran pada lintasan ini mengalami kalibrasi sebanyak tiga kali. Hal ini dikarenakan bentuk topografi yang miring, batuan keras yang nampak dipermukaan dengan kondisi cuaca pada saat itu adalah hujan, sehingga elektroda sebagian terendam air.

Lapisan atas lintasan ini berdasarkan litologinya di dominasi oleh clay dan limestone. Lapisan ini juga dipengaruhi oleh lapisan air yang banyak terdapat dibawahnya. Lapisan ini tergolong padat, meski tidak kompak. Lapisan dibawahnya terdiri dari lapisan air dengan nilai resistivitas 0.3-1,24 $\Omega \mathrm{m}$. Pada lapisan ini juga terlihat dominasi clay $6,31-32,1 \Omega \mathrm{m}$. Batuan yang lebih padat terdeteksi pada jarak 100-120 meter dan kedalaman 15-20 meter, yang teridentifikasi sebagai limestone.

Batuan cadas keras berada pada kedalaman 20 meter kebawah pada jarak 160-200 meter. Dari data terlihat bahwa di banyak bagian didominasi batuan berturut-turut clay, lanau, limestone, dan air. Batuan dasar rata-rata terdapat pada kedalaman 40-60 meter dibawah permukaan. Lintasan 3 ini memiliki banyak lapisan batuan padat, terlihat dari kenampakan di permukaannya. Akan tetapi di beberapa bagian terlihat lapisan bawah lebih basah/mengandung air dibandingkan lapisan di atasnya. Hal ini diprediksi berpotensi mengalami gerakan tanah.

Resistivitas semu (apparent resistivity) dipengaruhi oleh jenis batuan yang berada di bawah permukaan. Apabila batuannya lebih berongga maka nilai resistivitasnya besar, sedangkan apabila batuan lebih kompak maka nilai 
resistivitasnya akan lebih kecil. Batuan yang lebih kompak akan lebih mudah mengalirkan arus daripada batuan yang berongga, sehingga nilai resistivitas batuan yang kompak akan lebih kecil. Resistivitas terhadap kedalaman tidak dapat kita peroleh hubungan secara langsung, karena masih tergantung dari jenis batuan yang dikandung di bawah permukaannya. Pada umumnya semakin ke dalam permukaan bumi maka batuan akan semakin kompak. Oleh karena itu resistivitas akan semakin kecil.

Data lapangan yang diperoleh dari semua lintasan di daerah penelitian menunjukkan pola yang hampir seragam. Nilai tahanan jenis batuan bervariasi tergantung jenis mineral, kekompakan, dan kadar airnya. Hal ini sesuai dengan Prasetiawati, 2004 yang menyatakan bahwa hal yang mempengaruhi nilai resistivitas semu adalah: (a)Ukuran butir penyusun batuan, semakin kecil besar butir maka kelolosan arus akan semakin baik, sehingga mereduksi nilai tahanan jenis. (b)Komposisi mineral dari batuan, semakin meningkat kandungan mineral clay akan mengakibatkan menurunnya nilai resisivitas. (c) Kandungan air, air tanah atau air permukaan merupakan media yang mereduksi nilai tahanan jenis. (d) Kelarutan garam dalam air di dalam batuan akan mengakibatkan meningkatnya kandungan ion dalam air sehingga berfungsi sebagai konduktor. (e) Kepadatan, semakin padat batuan akan meningkatkan nilai resistivitas.

Lintasan 1 menunjukkan dominasi batuan clay, limestone, dan andesit. Hal ini sesuai dengan tabel batuan Reynold, Struktur yang sama juga terlihat mendominasi lintasan 2 dan 3.. Range resistivitas lokasi penelitian bervariasi antara 0,1 - $6000 \Omega \mathrm{m}$. Berdasarkan data tersebut dapat diklasifikasikan litologi daerah penelitian sebagai berikut:

Tabel 4.1. Litologi hasil penelitian

\begin{tabular}{|l|l|}
\hline Jenis Batuan & Resistivitas $(\mathbf{\Omega m})$ \\
\hline Clay basah & $<10$ \\
\hline Clay Padat & $10-70$ \\
\hline Limestone & $70-200$ \\
\hline Andesit & $>200$ \\
\hline
\end{tabular}

Berdasarkan litologi yang telah diklasifikasikan, maka dapat diperkirakan rancangan bangunan yang akan didirikan. Menurut Hutagalung, 2013 Diperlukan perencanaan pembangunan yang cukup matang untuk mencegah timbulnya perubahan bentuk yang kemudian akan menyebabkan penurunan pada bangunan. 
Suatu bangunan yang dibangun tanpa memperhatikan struktur tanah dan tata lingkungan maka akan memiliki resiko yang lebih besar terhadap kerusakan akibat dari gempa maupun penurunan tanah. Sedangkan menurut Sudarsono, 1984 Tanah selalu mempunyai peranan penting pada suatu lokasi pekerjaan konstruksi. Tanah adalah pondasi pendukung suatu bangunan atau bahan konstruksi dari bangunanan itu sendiri.

\section{KESIMPULAN}

1. Nilai tahanan jenis (resistivitas) batuan daerah penelitian berkisar antara $0,9-$ $6000 \Omega m$

2. Struktur batuan daerah penelitian di dominasi oleh clay, limestone, dan batuan dasar andesit

3. Struktur permukaan umumnya clay lunak, hanya dibeberapa bagian terdapat batuan limestone dan batuan beku andesit. Batuan dasar bervarisi terdapat di kedalaman 45-60 meter di bawah permukan. Melihat tingkat kemiringan lahan di beberapa tempat dan kondisi lapisan batuan dibawah permukaan, ada indikasi potensi terjadi gerakan tanah.

\section{DAFTAR PUSTAKA}

Azhar, Gunawan Handayani,2004. Penerapan metode geolistrik konfigurasi schlumberger untuk menentukan tahanan jenis batubara. Institut Teknologi Bandung(ITB). Bandung.

Broto,Surdaryo, Rohima Sera Afifah. Pengolahan data geolistrik dengan metode schlumberger. Vol.29. 2008. Undip.

Dobrin, Milton B. 1976. Introduction to Geophysical Prosoecting, McGraw-Hill international, USA

Geophysical Consulting and Instrument Services http://www.geocis.net http://geocis.indonetwork.co.id

Gunawan, Wawan, 2000, Eksplorasi Gaya Berat \& Magnetik, Penerbit ITB: ITB. Team Jurusan Teknik Geofisika, 2005, Buku Panduan Kuliah Lapangan Teknik Geofisika

Hendra, Lilik dan Arif, Idam. 1990. Monograf Geolistrik Tahanan Jenis, Laboratorium Fisika Bumi ITB, Bandung. 
Mulyo, Agung, 2009, Pengantar Ilmu Kebumian, pengetahuan geologi untuk Pemula, Pustaka Setia: Bandung

Pujiastuti,D.Indrawati, Edwiza.D, dan Mustafa, B, 2009, Penentuan Kedalaman Bidang Gelincir Derah Rawan Gerakan Tanah dengan Metoda Tahanan Jenis (Studi Kasus pada Dua Titik Pengamatan di Kampus Unand Limau Manis Padang), Prosiding Seminar Nasional Fisika Universitas Andalas Padang.

Kodoatie, Robert J.1995. Pengantar Hidrogeologi. Andi, Yogyakarta.

Keller, 1977, Electrical Methods in Geophyssical Prospecting, Pergamon Press: New York

Reynold, J.M., 1997. An Introduction to Applied and Environmental Geophysics, John Wiley \& Sons Ltd., UK.

Santoso, Djoko. 2002. PengantarGeofisika. Institut Teknologi Bandung: Bandung.

Shima, Hiromasa. 1990. Two Dimensional Automatic Resistivity Inversion Technique Using Alpha Centerss, Scc. Expl. Geophycs.

Seyhan, Ersin. 1990. Dasar-dasar Hidrologi. Gajah Mada University Press, Yogyakarta.

Sudaryo Broto, dkk, majalah teknik. Vol 29 no.2 th 2008, ISSN 08521697).

Sultan, 2009, Jurnal enjinering,vol:9

Tanudidjaja, Makmu. 1994. Ilmu Pengetahuan Bumi dan Antariksa. Balai Pustaka, Jakarta.

Telford, W.M., Geldart., L.P, R.E., and Keys,.DA., 1976, Applied Geophysics, Cambride University press, Cambridege

Verhoef, P.N.,1994.GeologiUntuk Teknik Sipil.Terjemahan. Diraatmaja.Cetakan ketiga, Erlangga.Jakarta 